\title{
Mersin (Myrtuscommunis L.) Mevyesinin Fiziksel, Mekanik, Renk ve Kimyasal Özellikleri
}

\section{Gülcan ŞAHİN1, Ebubekir ALTUNTAŞ2 $2^{\circ}$, Hakan POLATCI ${ }^{3}$}

Tokat Gaziosmanpaşa Üniversitesi, Ziraat Fakültesi, Biyosistem Mühendisliği Bölümü, 60250, Tokat

https://orcid.org/0000-0002-5855-8547, https://orcid.org/0000-0002-2568-9647, https://orcid.org/0000-0003-3835-1538

$\bowtie$ : ebubekir.altuntas@gop.edu.tr

\section{ÖZET}

$\mathrm{Bu}$ çalışmada, beyaz ve siyah mersin (Myrtuscommunis L.) meyvelerinin bazı biyoteknik (fiziksel, mekanik ve kimyasal) özellikleri incelenmiştir. Çalışmada beyaz ve siyah mersin meyvelerinin fiziksel özellikleri (geometrik, hacimsel ve renk karakteristikleri olarak geometrik ortalama çap, küresellik, yüzey alanı, ağırlık, hacim, meyve ve yığın hacim ağırlığı), ( $L, a, b$, Kroma, Hue açısı ve kahverengileşme derecesi renk karakteristikleri) ölçülmüştür. Mekanik özellikler olarak meyvelerin saptan kopma direnci, delme ve sıkıştırma kuvveti, deformasyon değerleri, ile kimyasal özellikler ise $\mathrm{pH}$, suda çözünebilir kuru madde miktarı (SÇKM) ve titre edilebilir asitlik (TEA) miktarı incelenmiştir. Beyaz ve siyah mersin meyvelerinin sıkıştırma ve delme testlerinde 20, 40 ve $60 \mathrm{~mm} \mathrm{~min}{ }^{-1}$ hızlarında elde edilen sıkıştırma ve delme kuvveti değerleri yükleme hızının artmasıyla birlikteartış göstermiştir. Beyaz mersin meyvelerinin sirasıyla SÇKM (\%13.63) ve TEA (0.510) değerleri, siyah mersin meyveleri değerlerinden sırasıyla (\%5.33 ve 0.205) daha yüksek belirlenmiştir. $\mathrm{pH}$ değeri, siyah mersin meyvelerinde (5.30), beyaz mersin meyvelerinden (4.48) daha yüksek bulunmuştur. Beyaz ve siyah mersin meyvelerinin biyoteknik özelliklerine ait sonuçların, hasat ve hasat sonrası ürün işleme, ürün kalitesi, tüketici istekleri ve ekonomik değer açısından göz önünde bulundurulması gerekmektedir.

\section{Araştırma Makalesi}

Makale Tarihçesi

Geliş Tarihi : 08.07.2019

Kabul Tarihi : 07.11.2019

\section{Anahtar Kelimeler}

Mersin

Hacim ağırlığı

Sıkıştırma testi

Suda çözünebilir kuru madde

Determination of Physical, Mechanical, Colour and Chemical Properties of Myrtle (Myrtus communis L.) Fruit

\section{ABSTRACT}

In this study, some biotechnical (physical, mechanical and chemical) properties of white and black myrtle (Myrtus communis L.) fruits were investigated. Physical properties of white and black myrtle (Myrtus communis L.) fruits as geometric and volumetric and color characteristics such as geometric mean diameter, sphericity, surface area, mass, volume, fruit and bulk densities, L, a, b, Chroma, Hue angle, Browning index color values), mechanical properties as fruit removal force, the puncture-compression force and deformations values, chemical properties $(\mathrm{pH}$, total soluble solid content (TSS) and titratable acidity) were examined. The compression and puncture force values of 20,40 and $60 \mathrm{~mm} \mathrm{~min}^{-1}$ of the compression and puncture tests in White and black myrtle (Myrtus communis L.) fruits increased with increasing loading speed. The mean values of TSS and TA obtained for White fruit samples were higher than those for black myrtle fruit samples. The $\mathrm{pH}$ value was higher in the black myrtle fruits than in the white myrtle fruits. The results of the biotechnical properties of white and black myrtle (Myrtus communis L.) fruits should be taken into consideration in terms of processing, quality, consumer requirements and economic value of the product at the harvest and post-harvest.

Research Article
$\begin{array}{ll}\text { Article History } \\ \text { Received } \quad: 08.07 .2019 \\ \text { Accepted } \quad: 07.11 .2019\end{array}$

Keywords
Myrtle
Bulk density
Compression test
Total soluble solid content




\section{GİṘŞ}

Türkiye; Avrupa, Asya ve Afrika kıtaları arasında geçiş konumunda bulunması, çeşitli iklim tiplerine sahip olması ve ekoloji farklılıkları nedeniyle önemli bir biyoçeşitliliğe sahiptir (Anonim, 2011). Ülkemizde yaklaşık 9000 farklı bitki türü doğal olarak yetişmekte, ancak bunlardan yeterli oranda yararlanılamamaktadır (İlçim ve Dığrak, 1998). Myrtaceae familyasinda yer alan mersin bitkisi (Myrtus communisL.), her dem yeşil, kısa boylu (bazen 1-3 m kadar boylanabilen) ve çalı formunda çok yıllık bir bitkidir. Bu familya yaklaşık 100 cins, 3000 tür içermekte ve çoğunlukla Avustralya'nın tropikal-subtropikal bölgelerinde ve Güney Amerika'da yetişmektedir (Anonim, 2011).

Mersin bitkisi, doğal olarak Akdeniz ülkeleri, Avustralya'da, Kuzey Amerika'nın ılıman bölgelerinde ve Orta Doğu ülkelerinde yayılma alanına sahiptir (Baytop, 1999; Jamoussi ve ark., 2005). Fransa, Türkiye, Tunus'un kıyı bölgeleri ile Fas'ta yabani olarak yetişmekte, İran, Eski Yugoslavya, Korsika, Italya ve İspanya'da ise bu bitkinin kültürel olarak üretimi yapılmaktadır (Jamoussi ve ark., 2005). Türkiye'de genel olarak "Mersin" adıyla bilinmesine karşın özellikle Güney sahillerimizde "Hambeles", "Adi Mersin" ve "Murt" adları ile de bilinmektedir (Oğur, 1994; Aydın ve Özcan, 2007). Mersin meyveleri, üzümsü meyve tipinde ve çoğunlukla siyahımsı mor renkli veya beyaz renkli olup, sonbaharda (Ekim ve Aralık ayları arasında) olgunlaşmaktadır (Anonim, 2011). Sert ve çok miktarda küçük tohum içeren meyveleri buruk bir lezzete sahiptir. Böceklerle tozlanmakta ve yaygın tohum dağıtıcıları kuşlar olmakla beraber, bazı memelilerin de tohum yaydıkları gözlemlenmektedir (Aronne ve Russo, 1997). Mersin bitkisinin taze veya kuru yapraklarının uçucu yağlar, şekerleme, kozmetik veya içecek sanayinde kullanılabilmektedir. Yapraklarından buhar distilasyonuyla elde edilen uçucu yağları, ayrıca parfüm endüstrisi için de çok önemlidir (Akgül ve Bayrak, 1989; Boelens ve Jimenez, 1992; Özek ve ark., 2000). Önemli aromatik ve tıbbi bitki olan mersin meyvesinin ekstraktları geleneksel olarak antiseptik, dezenfektan ilaç ve hipoglisemik madde olarak kullanılmaktadır (Elfellah ve ark., 1984). Yüksek miktarda $A, B$ ve $C$ vitaminleri; \%0.3-0.5 oranında uçucu yağ, myrtenol, alpha-pinene, beta-pinene, geraniol vb., şeker ve organik asitler (sitrik asit ve malik asit) içermektedir (Erlaçin ve Erciyas, 1978; Doğan, 1978). Mersin bitkisinde; antosiyaninin pigmentleri; petunidin, delfinidin, peonidin, malvidin, siyanidin-3monoglukozid ve siyanidin-3, 5-diglukozid ile tanenler en yüksek oranda yapraklarda \%14-19 civarında ve köklerde ise \%6.64-6.8 oranında bulunmaktadır (Erlaçin ve Erciyas, 1978; Diaz ve Abeger, 1986).
Tarımsal materyallerin biyo-teknik özellikleri (mekanik, fiziksel, hidrodinamik ve aerodinamik, kimyasal, akustik, optik vb.) hasat, harman, sinıflandırma, taşıma-iletim, ürün işleme, depolama, paket ve ambalajlama gibi birçok hasat sonrası teknolojik çalışma ve sistemlerde kullanılacak olan makina ve tesislerin projelendirilmesi, tasarım, imalat ve geliştirilmesinde kullanılmaktadır. Ayrıca, ilgili makina, tesis ve sistemlerin iş başarılarının belirlenmesi, ürün işleme ve ürün kalite ve kontrol aşamaları ile sonuçta tüketiciye sunulmasında, ürün kalitesinin korunması gibi birçok işlemde önemli ve belirleyici bir rol oynamaktadır.

Son yıllarda, farklı meyve türlerine ait biyo-teknik özelliklere dayalı olarak birçok çalışma yapılmış olsa da, mersin meyvesinin fiziksel, mekanik, kimyasal özellikleriyle ilgili sınırlı birkaç çalışma yapılmıştır (Özcan ve Akbulut, 1998; Aydin ve Özcan, 2007; Hacıseferoğulları ve ark., 2012; Yıldırım ve ark., 2013).Mersin bitkisinin uçucu yağ kompozisyonları ve uçucu yağ içeriklerinin (çiçek, yaprak, meyve ve taze dalları için) araştırılması konusunda birçok araştırmacı (Özek ve ark., 2000; Pezhmanmehr ve ark., 2009; Serçe ve ark., 2010; Ghannadi ve Dezfuly, 2011) çalışma yapmıştır. Bu çalışmada, mersin meyvelerinin biyo-teknik özellikleri kapsamında, fiziksel ve kimyasal özelliklerinin yanısıra mekanik özelliklerinin de incelenmesi amaçlanmıştır.

\section{MATERYAL ve YÖNTEM}

Mersin meyvelerinin biyoteknik özelliklerine ait fiziksel ve mekanik analizler, Tokat Gaziosmanpaşa Üniversitesi, Biyosistem Mühendisliği Bölümü, Biyolojik Malzeme Laboratuvarı'nda; kimyasal analizler ise Bahçe Bitkileri Bölümü'ne ait Meyvecilik Araştırma Laboratuvarı'nda yürütülmüştür. Çalışmada, deneme materyalleri olarak Mersin ilinin Erdemli ilçesinde doğal olarak yetişen beyaz ve siyah mersin bitkilerinden toplanan meyveler kullanılmıştır. Beyaz ve siyah mersin bitki habituslarının sarkık yapıda oldukları belirtilmiştir (Yıldırım ve ark., 2013). Beyaz mersin meyvelerinin derimi 12 Eylül 2016 tarihinde, siyah mersin meyvelerinin hasadı ise 6 Aralık 2016 tarihinde yapılmıştır. Siyah mersin meyveleri, tam olgunluk döneminde hasat edilmiştir. Beyaz mersin meyveleri çok olgunlaştıklarında yumuşama göstermesi nedeniyle fiziksel ve diğer testlerin sağlıklı yürütülemeyeceği düşünüldüğünden, tam olgunlaşma zamanından 1 hafta önce hasat edilmiştir. $\mathrm{Bu}$ çalışmada beyaz ve siyah mersin meyvelerine ait örneklerin nem içerikleri etüvde $70^{\circ} \mathrm{C}$ sıcaklıkta 24 saat bekletilerek belirlenmiştir. Beyaz mersin meyve örneklerinin hasat sonrası nem içeriği \%79 $\% 0.1$ iken, siyah mersin meyvesi örneklerinin nem içeriğinin ise $\% 62 \pm 0.1$ olduğu belirlenmiştir. Dolayısıyla beyaz mersin meyveleri hasat zamanına göre de daha fazla 
nem içermektedir.

Fiziksel özelliklere ait ölçümlerden boyut özellikleri ve meyve ağırlığının belirlenmesi için, 100 adet meyve örneği tesadüfi olarak seçilmiş, ölçümlerde ortalama, maksimum ve minimum değerler ile standart hata değerleri belirlenmiştir. Meyvelerin uzunluk ve genişliği dijitalkumpas ile ölçülmüştür. Meyveler iki boyutlu olarak incelenmiş, kalınlık boyutu dikkate alınmamıştır (Hacıseferoğulları ve ark. 2012). Meyve ağırlı̆̆ı ölçümlerinde; dijital hassas terazi ile ölçüm yapılmadan önce meyve sapları kopartılmıştır. Ürünlerin eksenel boyutlarının (uzunluk ve genişlik(çap)) ölçümü ve ağırlık ölçümleri ayrı ayrı yapılmıştır. Geometrik ortalama çap, küresellik, yüzey alanı ve meyve hacmi aşağıdaki eşitlikler yardımıyla Mohsenin (1980)'e hesaplanmıştır.

$G c=\left(U G^{2}\right)^{1 / 3}$

$K r=(G c ̧ / U) .100$

$Y A=\pi . G c^{2}$

$H=\Pi / 6 .\left(U G^{2}\right)$

Burada; $G c ̧$ : Geometrik ortalama çap $(\mathrm{mm}), U$ : Uzunluk (mm), $G$ : Genişlik (mm), $K r$ : Küresellik (\%), $Y A$ : Yüzey alanı $\left(\mathrm{cm}^{2}\right)$ ve $H$ : Hacim $\left(\mathrm{cm}^{3}\right)^{\prime}$ dir.

Beyaz ve siyah mersin meyvelerinin hacim ağırlıklarının belirlenmesinde, sıvı yer değiştirme metodu kullanılmıştır. Meyve hacim ağırlığı ölçümleri için; dereceli ölçü kabına $40 \mathrm{ml}$ saf su konularak üzerine ağırlığ belirlenmiş olan mersin meyve örnekleri konulmuştur. Daha sonra saf su içine atılan meyvenin taşırdığı hacim, ölçülü pipet kullanılarak belirlenmiş, ağırlık ve hacim oranlamasıyla meyve hacim ağırlığı bulunmuştur (Mohsenin, 1980). Mersin meyvelerinin yığın hacim ağırlıkları için hektolitre yöntemi kullanılmıştır. Bu amaçla, 1/4 litrelik hektolitre kabına meyve örneklerinin belirli bir yükseklikten bir huni yardımıyla tepeleme doldurulmasıyla, kap hacmi ve meyve örnek ağırlığı dikkate alınarak $\mathrm{kg} \mathrm{m}^{-3}$ cinsinden meyvenin yığın hacim ağırlıkları belirlenmiştir (Altuntas ve Yıldız, 2007).

Beyaz ve siyah mersin meyvelerinin meyve kabuğu ve kabuk altı (meyve eti) renk özelliklerinin ( $L$, $a$ ve $b$ ) belirlenmesinde, Minolta (Model CR-400, Tokyo, Japonya) renk ölçer kullanılmıştır (McGuire, 1992). Hazırlanan renk skalasına göre; $L$ değeri parlaklık (0 karanlık, 100 aydınlık); a değeri kırmızı/yeşil renk (+ değer kırmızılığı, - değer ise yeşilliği); $b$ değeri sarı/mavi rengi (+ değer sarılığı, - değerler maviliği) göstermektedir. Kroma ( $C$ ) ve Hue açısı $(h)$ değerleri, Bernalte ve ark. (2003)'ın belirttiği aşağıdaki eşitliklerle elde edilmiştir. Kahverengileşme derecesi (Browning Index, BI), kahverengi rengin saflı̆̆ını temsil eder ve esmerleşme ile ilişkili önemli bir parametre olarak kabul edilmektedir (Mohammadi ve ark., 2008).

$$
\begin{aligned}
& C=\left[a^{2}+b^{2}\right]^{1 / 2} h=\left[\tan ^{-1} \frac{b}{a}\right] \\
& B I=\frac{[100(x-0.31)]}{0.17} \quad x=\frac{(a+1.75 L)}{(5.645 L+a-3.012 b)}
\end{aligned}
$$

Mekanik özelliklere ait ölçümlerde, meyvelerin saptan kopma direnci, meyve delme testi, sıkıştırma testi ve statik sürtünme katsayısı ölçümleri yapılmıştır. Meyve kopma direnci, meyvelerin sap kısmından açısal ve eksenel olarak ayrılması için dijital kuvvetölçer (çeki dinamometresi) (10 N, Tronic; HF-50, 100 N, Tayvan) kullanilarak Newton (N) cinsinden ifade edilmiştir. Sıkıştırma ve delme testlerinde motorlu otomatik kontrollü biyolojik materyal test cihazı ve kullanılmıştır (Şekil 1).
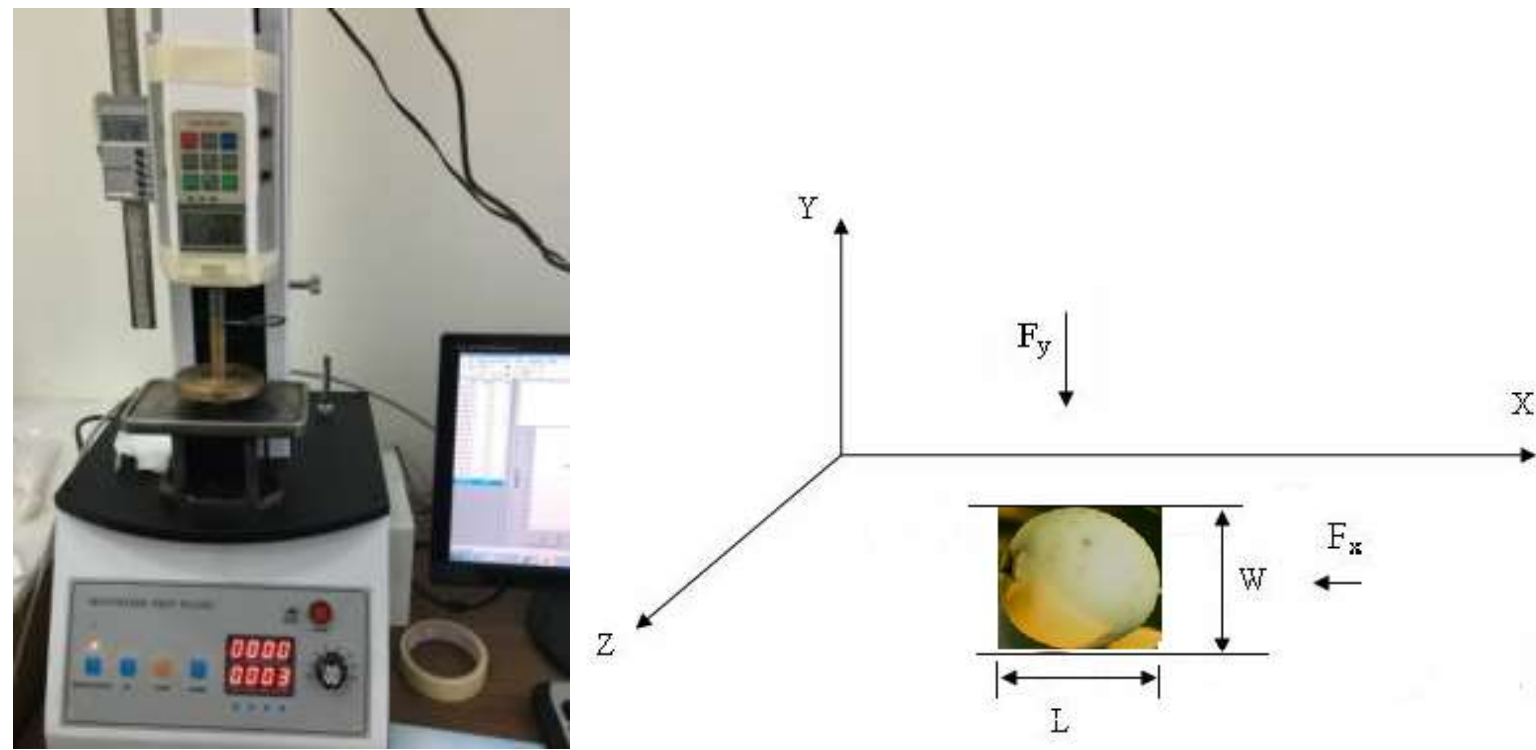

Şekil 1. Biyolojik malzeme test cihazı ve beyaz mersin meyvesinin eksenel boyutları $\left(X\right.$-, $Y$-) ile eksenel kuvvetlerin $\left(F_{X}\right.$, ve $F_{y}$, gösterimi.

Figure 1. Biological materials test device, display of axial dimensions $\left(X^{-}, Y^{-}\right)$and forces $\left(F_{X}\right.$ and $\left.F_{y}\right)$ of white myrtle fruit, 
Delme testleri için $1.2 \mathrm{~mm}$ çapında çelik iğne uç ve sıkıştırma testleri için $75 \mathrm{~mm}$ çaplı dairesel pirinç plaka kullanılmıştır. Denemelerde beyaz ve siyah mersin meyvelerinin $X^{-}$ve $Y^{-}$eksenine göre sıkıştırma ve delme testleri sonucu kuvvet ve deformasyon ölçümleri yapılmış ve okuma değerleri ise sirasıyla $\mathrm{N}$ ve $\mathrm{mm}$ cinsinden verilmiştir (Şekil 1).

Delme ve sıkıştırma testi sonucu delme kuvveti veya direnci, farklı yükleme hızlarında $\left(20 \mathrm{~mm} \mathrm{~min}^{-1}, 40\right.$ $\mathrm{mm} \min ^{-1}$ ve $60 \mathrm{~mm} \mathrm{~min}^{-1}$ ) belirlenmiş, delme ve sıkıştırma testleri sadece meyve kabuğu üzerinden yapılmıştır. Bu yükleme hızları, genel olarak biyolojik malzemelerde uygulanan yükleme hızları olup, beyaz ve siyah mersin meyve örnekleri için 7 tekerrürlü olarak denemeler yapılmış ve ölçülen değerlerin ortalamaları dikkate alınmıştır.

Meyvelerin sürtünme katsayısı ölçümü için, eğimli masa düzeneği kullanılmıştır. Farklı sürtünme yüzeyleri üzerinde yer alan meyve örneklerinin hareketine izin verecek şekilde eğimli masa bir kol ile hareketlendirilerek, ilk hareketin sağlandığ durumda eğimli masanın tanjantı (eğim açısı), statik sürtünme katsayısı olarak kullanılmıştır.

Kimyasal ölçümlerden, $\mathrm{pH}$ değeri, meyve örneklerinin bir blendir ile parçalanarak elde edilen meyve suyunun bir pH metre (HI9321, Hanna, ABD)ile doğrudan ölçümüyle belirlenmiştir (Cemeroğlu, 2013). Suda çözünebilir kuru madde miktarı (SÇKM) değeri ise meyve suyunun dijital bir refraktometre ile ölçümüyle belirlenmiş ve (PAL-1, Atago McCormick Fruit Tech., Yakima, Wash., ABD) SÇKM (Brix) değeri \% olarak ifade edilmiştir. Titre edilebilir asitlik (TEA) miktarı ise meyve suyu örneğinden 10 $\mathrm{ml}$ alınarak üzerine $10 \mathrm{ml}$ saf su eklenmiş $\mathrm{pH}$ değeri 8.1'e ulaşıncaya dek $0.1 \mathrm{~mol} \mathrm{~L}^{-1} \mathrm{NaOH}$ çözeltisi ile titre edilmiş ve aşağıdaki formül ile hesaplanmıştır. Sonuçlar malik asit cinsinden (g malik asit $100 \mathrm{~g}^{-1}$ ) ifade edilmiştir. (Cemeroğlu, 2013).

$T A=\left[\frac{S x N x E}{B} x 100\right]$
TA: Asit miktarı (g malik asit $100 \mathrm{~g}^{-1}$ )

$S$. Harcanan sodyum hidroksidin miktarı (mL)

$N$ : Harcanan sodyum hidroksidinnormalitesi

$E$. İlgili asidin equivalent değeri (malik asit için 0,067 g alınmıştır)

$B$. Alınan örnek miktarı (mL)

Yapılan çalışmada, beyaz ve siyah mersin meyvelerinin fiziksel, mekanik ve kimyasal özelliklerinin belirlenmesine yönelik parametrelere ait veriler, Excel programı kullanılarak değerlendirilmiştir. Beyaz ve siyah mersin meyvelerinin genotip olarak özellikleri farklı olduğu için sadece temel istatistik hesaplamalar olarak (ortalama ve standart hata değerleri) verilmiş olup, iki genotip açısından herhangi istatistiksel bir karşılaştırma yapılmamıştır. Mekanik ölçümlerde yükleme hızı ve yükleme ekseni dikkate alındığı için istatistiksel analiz SPPS paket programı ile yapılarak, çoklu karşılaştırma için ise 'Duncan testi' kullanılmıştır.

\section{ARAŞTIRMA BULGULARI ve TARTIŞMA}

\section{Fiziksel özellikler}

Çalışmada siyah ve beyaz mersin meyve örneklerinin fiziksel özellikleri; geometrik özellikler, hacimsel özellikler ve renk özellikleri olarak gruplandırılıp değerlendirilmiştir. Geometrik özellikler açısından uzunluk ve genişlik değerlerinin beyaz mersin meyvelerinin siyah renklilere göre $\% 65.63$ ve $\% 53.84$ oranlarında daha iri olduğu görülmüştür. Geometrik ortalama çap ve yüzey alanı değerlerinin, beyaz mersin meyvelerinde, siyah olanlara göre daha büyük değerlerde olduğu; küresellik değerlerinde ise, siyah mersin meyvelerinin beyaz olanlara göre daha büyük değerlerde olduğu belirlenmiştir. Geometrik ortalama çap değerleri açısından beyaz mersin meyveleri, siyah mersin meyvelerine göre \%59.77oranında, yüzey alanı ortalama değerleri 2.56 kat daha yüksek değerler verirken, küresellik değerlerinde ise, siyah mersin meyveleri, beyaz olanlara göre \%4.08 oranında daha yüksek değerler vermiştir (Çizelge 1).

Cizelge1. Beyaz ve siyah mersin meyvelerinin geometrik özellikleri

Table 1. Geometric properties of white and black mrytle fruits.

\begin{tabular}{l|rrrr|rrrr}
\hline \multirow{2}{*}{ Geometrik özellikler } & \multicolumn{4}{|c|}{ Beyaz mersin meyvesi } & \multicolumn{3}{c}{ Siyah mersin meyvesi } \\
\cline { 2 - 9 } & \multicolumn{1}{|c}{ Max. } & \multicolumn{1}{c}{ Min. } & \multicolumn{1}{c}{ Ort. } & \multicolumn{1}{c}{ SEM } & Max. & \multicolumn{1}{c}{ Min. } & \multicolumn{1}{c}{ Ort. } & SEM \\
\hline Uzunluk $(\mathrm{mm})$ & 19.68 & 11.04 & $\mathbf{1 5 . 9 0}$ & 0.14 & 11.19 & 8.17 & $\mathbf{9 . 6 0}$ & 0.07 \\
Genişlik/çap $(\mathrm{mm})$ & 15.62 & 9.34 & $\mathbf{1 2 . 8 3}$ & 0.12 & 10.25 & 6.60 & $\mathbf{8 . 3 4}$ & 0.06 \\
Geometrik ortalama çap $(\mathrm{mm})$ & 16.25 & 10.90 & $\mathbf{1 3 . 7 4}$ & 0.11 & 16.22 & 11.00 & $\mathbf{8 . 6 0}$ & 0.05 \\
Küresellik (\%) & 96.90 & 75.71 & $\mathbf{8 6 . 2 1}$ & 0.37 & 98.91 & 78.58 & $\mathbf{8 9 . 7 3}$ & 0.47 \\
Yüzey alanı $\left(\mathrm{cm}^{2}\right)$ & 8.29 & 3.73 & $\mathbf{5 . 9 7}$ & 0.10 & 3.28 & 1.54 & $\mathbf{2 . 3 3}$ & 0.03 \\
\hline
\end{tabular}

SEM: standart hata (standard error of mean)

Hacıseferoğulları ve ark. (2012), beyaz mersin meyvelerinin geometrik ortalama çap, küresellik ve projeksiyon alanı değerlerini sırasıyla $12.31 \mathrm{~mm}, 0.90$ ve $1.65 \mathrm{~cm}^{2}$ olarak, siyah mersin meyvelerinde ise sirasiyla $12.73 \mathrm{~mm}, \quad 0.85$ ve $1.48 \quad \mathrm{~cm}^{2}$ olarak saptamışlardır. Araştırmacılar, siyah mersin meyvelerinin beyaz renklilere göre geometrik ortalama çap değerlerini daha büyük, aksine 
küresellik ve projeksiyon alanı değerlerini ise daha düşük -değerde bulmuşlardır. Bu çalışmada ise, beyaz mersin meyvelerinin, geometrik ortalama çap değeri ve yüzey alanı değerleri siyah renklilere göre daha büyük, küresellik değerleri ise daha düşük bulunmuştur. Literatür ile kıyaslandığında bu çalışmanın sonuçlarındaki farklılıkların, meyvelerin genotip, iklim ve yetiştiği çevre faktöründen kaynaklanmış olacağı düşünülmektedir. Aynı zamanda, aynı yöre iklim ve çevre koşullarında da olsa, genotip ve genetik faktörlerin sonuçlarda farklılığa neden olacağı söylenebilir.

Hacimsel özellikler açısından, çalışmada ağırlık (kütle) ve hacim değerlerinin beyaz mersin meyvelerinde, yığın hacim ağırlığı ve meyve hacim ağırlıkları değerlerinin ise siyah mersinde daha yüksek olduğu bulunmuştur (Çizelge 2).

Çizelge 2. Beyaz ve siyah mersin meyvelerinin hacimsel özellikleri

Table 2. Volumetric properties of white and black mrytle fruits.

\begin{tabular}{|c|c|c|c|c|c|c|c|c|}
\hline \multirow[t]{2}{*}{ Hacimsel özellikler } & \multicolumn{4}{|c|}{ Beyaz mersin meyvesi } & \multicolumn{4}{|c|}{ Siyah mersin meyvesi } \\
\hline & Max. & Min. & Ort. & SEM & Max. & Min. & Ort. & SEM \\
\hline $\mathrm{A} \breve{g}$ & 2.10 & 0.78 & 1.31 & 0.03 & 0.55 & 0.15 & 0.35 & 0.01 \\
\hline $\mathrm{Hac}$ & 2.26 & 0.68 & 1. & 0.0 & 0.56 & 0.18 & 0.34 & 0.01 \\
\hline Yığır & 450.8 & 415.9 & 432.6 & 3.54 & 698.6 & 633.4 & 667.7 & 6.22 \\
\hline Meyve hacim ağırlığ $\left(\mathrm{kg} \mathrm{m}^{-3}\right)$ & 986.3 & 727.3 & 838.4 & 24.50 & 1300.0 & 656.7 & 963.9 & 70.67 \\
\hline
\end{tabular}

SEM: standart hata (standard error of mean)

Yapılan çalışmalarda, Yıldırım (2012) yaptığı çalışmada Karaisalı, Tarsus, Yanıkışla ve Erdemli yöreleri için renk ayrımı yapmadan mersin meyvelerinin ağırlıklarını $0.26 \mathrm{~g}$ ile $2.01 \mathrm{~g}$ aralığında açıklamıştır. Bu çalışmada da meyve ağırlıklarının göre, beyaz mersin meyvesinde daha yüksek, siyah renkli olanlar ise literatür değerleri aralığında olduğu görülmüştür. Yine Özcan ve Akbulut (1998), beyaz mersin meyveleri ile mor büyük ve küçük boyuttaki meyve (gerçek) hacim ağırlıklarını sırasıyla, 1006.5 $\mathrm{kg} \quad \mathrm{m}^{-3}, \quad 1010.0 \quad \mathrm{~kg} \quad \mathrm{~m}^{-3}$ ve $858.0 \quad \mathrm{~kg} \mathrm{~m}^{-3}$ olarak belirlemişlerdir. Hacıseferoğulları ve ark. (2012) ise beyaz ve siyah mersin meyvelerinin yığın hacim ağırlığı değerlerini sırasıyla $431.0 \mathrm{~kg} \mathrm{~m}^{-3}$ ve $426.5 \mathrm{~kg}$ $\mathrm{m}^{-3}$, meyve hacim ağırlığı değerlerini ise sirasıyla $752.1 \mathrm{~kg} \mathrm{~m}^{-3}$ ve $757.5 \mathrm{~kg} \mathrm{~m}^{-3}$ olarak bulmuşlardır. Bu çalışmada bulunan meyve hacim ağırlıkları Özcan ve Akbulut (1998)'un sonuçlarından daha küçük, aksine Hacıseferoğulları ve ark. (2012)'ın bulgularından ise daha yüksek değerde bulunmuştur. Çalışmanın elde edilen sonuçları ile literatürler arasındaki farklılıkların meyvelerin genetik, çevre ve iklim faktörlerinden kaynaklandığı düşünülmektedir.

\section{Mekanik özellikler}

Meyvenin saptan kopma direnci açısından, mersin meyvelerinin, kültüre alınarak ticari amaçlı yetiştirilmesi durumunda, hasadına yönelik mekanizasyonunda kullanılacak makine ve sistemlerdeki bitkiye özgü hasat ölçütlerinden birisi olarak önemli olup, belirlenmesi gerekmektedir. Çalışmada, meyvenin saptan kopma direnci, beyaz ve siyah mersin meyvelerinin farklı büyüklük ve ağırlıkta olması nedeniyle farklı değerler vermiştir. Ayrıca yöre iklim ve yetişme koşulları beraber genetik faktörler de bu ölçüm değerlerinin farklılık göstermesine neden olabilmektedir. Beyaz mersin meyvelerinin sapa tutunma kuvveti $(3.68 \mathrm{~N})$, siyah mersin meyvelerine $(1.26 \mathrm{~N})$ göre daha yüksek değerde olup, beyaz mersin meyvelerinin siyah olanlara göre 3 kat daha dirençli bulunmuştur (Çizelge 3).

Yapabildiğimiz literatür taramalarında, mersin bitkisi meyvelerine ait meyvenin saptan kopma dirençlerine ait herhangi bir veri bulunamamıştır. Yapılan bir çalışmada, farklı organik olarak yetiştirilen sofralık üzüm çeşitleri; Vitisvinifera L. cv. Buca Razakı, Vitisvinifera L. cv. Çeşme Pembesi, Vitisvinifera L. cv. Siyah Gemre, Vitisvinifera L. cv. Kırmızı Şam, ve Vitisvinifera L. cv. Pek Üzümü'nün hasat edilen meyvelerin saptan kopma direnci değerleri 3.4 ile $4.3 \mathrm{~N}$ aralığında bulunmuştur (İşçi ve ark., 2014). Literatür sonucuna göre, mersin meyvelerinin saptan kopma dirençleri, sofralık üzüm çeşitlerinin meyve saptan kopma dirençleri aralığında olduğu gözlenmiştir.

Cizelge 3. Beyaz ve siyah mersin meyvelerinin saptan kopma direncine ait ortalama değerler Table 3. Means of fruit removal forces of white and black mrytle fruits.

\begin{tabular}{|c|c|c|c|c|c|c|c|c|}
\hline \multirow[t]{2}{*}{ Mekanik özellik } & \multicolumn{4}{|c|}{ Beyaz mersin meyvesi } & \multicolumn{4}{|c|}{ Siyah mersin meyvesi } \\
\hline & Max. & Min. & Ort. & SEM & Max. & Min. & Ort. & SEM \\
\hline Meyve saptan kopma direnci (N) & 4.45 & 2.68 & 3.68 & 0.08 & 1.83 & 0.92 & 1.26 & 0.04 \\
\hline
\end{tabular}

SEM: standart hata

Sürtünme katsayısı açısından, beyaz mersin meyvelerinin farkl sürtünme yüzeylerindeki statik sürtünme katsayısı ortalama değerleri; galvanizli sac,
PVC ve lastik yüzeyler için sırasıyla $0.329,0.285$ ve 0.336; siyah renkli meyvelerde ise, aynı yüzeyler için sirasiyla $0.294,0.267$ ve 0.398 olarak bulunmuştur. 
Siyah mersin meyvelerinin galvanizli sac ve PVC sürtünme yüzeyleri için sürtünme katsayısı değerleri beyaz renkli meyvelere göre daha düşük bulunmuştur. Bulunan sonuçların, çalışmada, siyah mersin meyveleri tam olgunluk zamanında hasat edilmişken, beyaz renkli meyveler ise tam olgunluk düzeyinden 1 hafta önce hasat edilmiş olmasından kaynaklanmış olacağı düşünülmektedir. Çalışmada, genel olarak, lastik yüzeyde meyvelerin yüzeye olan tutunmasının diğer parlak, kaygan ve daha düzgün yüzeye sahip olan galvanizli sac ve PVC yüzeylerden daha fazla olduğunu göstermiştir (Çizelge 4).

Çizelge 4. Beyaz ve siyah mersin meyvelerinin farklı yüzeylerdeki sürtünme katsayısı değerleri

Table 4. Coefficients of friction values of white and black mrytle fruits on different surfaces.

\begin{tabular}{l|rrrr|rrrr}
\hline \multirow{2}{*}{ Sürtünme Yüzeyleri } & \multicolumn{4}{|c|}{ Beyaz mersin meyvesi } & \multicolumn{4}{c}{ Siyah mersin meyvesi } \\
\cline { 2 - 9 } & Max. & Min. & Ort. & SEM & Max. & Min. & Ort. & SEM \\
\hline Galvanizli sac & 0.40 & 0.28 & O.33 & 0.011 & 0.31 & 0.28 & O.29 & 0.003 \\
PVC & 0.32 & 0.23 & $\mathbf{O . 2 9}$ & 0.009 & 0.29 & 0.25 & 0.27 & 0.003 \\
Lastik (kauçuk) & 0.38 & 0.29 & $\mathbf{0 . 3 4}$ & 0.007 & 0.42 & 0.38 & $\mathbf{0 . 4 0}$ & 0.003 \\
\hline
\end{tabular}

SEM: standart hata

Hacıseferoğulları ve ark (2012), beyaz mersin meyvelerinin statik sürtünme katsayısı değerlerini galvanizli sac, sac ve kontrplak yüzeyler için sırasıyla $0.200,0.230$ ve 0.280 ; siyah mersin meyvelerinde ise sırasıyla $0.260,0.290$ ve 0.330 olarak belirlemişlerdir. $\mathrm{Bu}$ çalışmada, her iki tip mersin meyvelerinin özellikle galvanizli sac için statik sürtünme katsayılarının literatür değerlerine göre daha yüksek olduğu bulunmuştur. Çalışma ile literatür arasındaki sonuçlardaki farklılıkların, bitkiye ait genotip özelliği, iklim koşulları ve yetiştiği çevre faktörlerinden kaynaklandığı düşünülmektedir. Ayrica beyaz mersin meyvelerinin tam olgunlaşmadan 1 hafta önce hasat edilmiş olmasına rağmen, siyah mersin meyvelerine göre özellikle galvaniz sac ve PVC sürtünme yüzeylerinde daha yüksek değerler, lastik yüzeyde ise daha düşük değerler vermiştir.

Delme testi açısından, çalışmada beyaz ve siyah mersin meyve örneklerine ait varyans analiz sonuçlarına göre, delme kuvveti ve deformasyon değerlerine yükleme hızının etkisi istatistiksel olarak önemsizken, yükleme ekseninin etkisi $p<0.01$ düzeyinde önemli bulunmuştur. Beyaz ve siyah mersin meyve örneklerinin yükleme hızlarına göre $X^{-}$ ekseni boyunca delme kuvveti ve deformasyon değerlerinin yükleme hızlarına bağlı olarak arttığı, deformasyon değerlerinin beyaz ve siyah mersin meyvelerinde de $Y$ - ekseninde de artma eğiliminde olduğu görülmüştür (Çizelge 5).

Beyaz mersin meyvesinde, delme testleri sonucu kuvvet değerlerinin $X^{-}$ekseni boyunca yükleme hızları değişimine göre $\% 23.47$ oranında artış; deformasyon değerinde ise \%85.23 değerinde artış göstermiştir. Delme kuvveti değerlerinin değişimi, $X^{-}$ ekseninde $Y$ - eksenine göre daha yüksek, deformasyon açısından ise $Y$ - ekseninde değişimin $X$ eksenine göre daha yüksek olduğu gözlenmiştir. Siyah mersin meyveleri için de $X$ - ekseni boyunca delme kuvveti değerlerinin artış gösterdiği, deformasyon değerlerinin ise $X^{-}$ve $Y^{-}$yükleme eksenleri boyunca yükleme hızı ile artış gösterdiği de belirlenmiştir. Siyah mersin meyvesinde, yükleme hızlarının değişimine göre delme kuvveti değerleri; $X$ ekseni boyunca \%6.85, deformasyon değerinde ise \%51.36 oranında artış göstermiştir (Çizelge 5).

Sıkıştırma testi açısından, beyaz mersin meyvelerinde sıkıştırma kuvveti değerlerine yükleme hızının etkisi $\mathrm{p}<0.01$ düzeyinde önemliyken, yükleme ekseninin etkisi istatistiksel olarak önemsiz bulunmuştur. Siyah mersin meyvesinde ise, sıkıştırma kuvveti değerlerine yükleme hızı ve yükleme ekseninin etkisi istatistiksel olarak önemsiz iken, deformasyon değerlerine yükleme hızının etkisi $\mathrm{p}<0.01$ düzeyinde önemli, sıkıştırma kuvvetine ise, yükleme hızının etkisi önemsiz bulunmuştur.

Beyaz ve siyah mersin meyvelerinin $X^{-}$ve $Y$-yükleme eksenleri boyunca sıkıştırma kuvveti ve deformasyon değerlerinin artış gösterdiği gözlenmiştir. Sıkıştırma kuvveti değerlerinin değişimi hem beyaz ve hem de siyah mersin meyvelerinde $X$ - ekseninde, $Y$ - eksenine göre daha yüksek iken, deformasyon değerlerinin değişimi, $Y$ - ekseninde $X$ - eksenine göre daha yüksek bulunmuştur (Çizelge 6). Hacıseferoğulları ve ark. (2012), beyaz ve siyah mersin meyvelerinin $50 \mathrm{~mm}$ min $^{-1}$ yükleme hızındaki sıkıştırma kuvveti değerlerini (rupture force) sirasiyla $2.06 \mathrm{~N}$ ile $1.77 \mathrm{~N}$ olarak bulmuşlardır. $\mathrm{Bu}$ çalışmada bulunan sıkıştırma kuvvet değerleri, Hacıseferoğulları ve ark. (2012)'nın bulguları ile kıyaslandığında, beyaz mersin meyvelerine göre daha yüksek, siyah renkli meyvelerde ise daha düşük elde edilmiştir. Çalışmada, sıkıştırma testleriyle bulunan kuvvet ve deformasyon değerlerinin özellikle, hasat sonrası bir kalite göstergesi olup, taşıma, ürün işleme, depolama, ambalajlama ve paketleme gibi uygulamalarda materyalin zedelenmeden tüketiciye ulaştırılmasında, önemli olup, dikkate alınması gereken özelliklerindendir.

Renk özellikleri açısından, beyaz ve siyah mersin meyvelerinin meyve kabuk ve meyve eti renk karakteristiklerine yönelik sonuçlarda, $L$ parlaklık 
değerleri, beyaz mersin meyvesinin daha yüksek değer verdiği ve meyve kabuk ve meyve eti için değerlerin sırasıyla; ortalama 71.14 ve 71.19 , siyah mersin meyvesinde ise sirasiyla ortalama 25.36 ve
44.16 olarak belirlendiği görülmüştür. $\mathrm{Bu}$ açıdan siyah mersin meyvesinde meyve eti meyve kabuk rengine göre \%74.13 oraninda daha koyu renktedir (Çizelge 7).

Çizelge 5. Beyaz ve siyah mersin meyvelerinin delme testi ve yükleme eksenlerine göre delme kuvveti ile deformasyon değerleri

Table 5. Puncture test, puncture force and deformation values of white and black myrtle fruits according to the loading axes.

\begin{tabular}{|c|c|c|c|c|c|c|c|c|}
\hline \multirow{3}{*}{ Delme testi } & \multirow{3}{*}{\multicolumn{2}{|c|}{ Yükleme ekseni }} & \multicolumn{3}{|c|}{ Beyaz mersin meyvesi } & \multirow{2}{*}{\multicolumn{3}{|c|}{$\begin{array}{l}\text { Siyah mersin meyvesi } \\
\text { Yükleme hızı }\left(\mathrm{mm} \mathrm{min}^{-1}\right)\end{array}$}} \\
\hline & & & Yükler & hizi $(m n$ & $\left.i n^{-1}\right)$ & & & \\
\hline & & & 20 & 40 & 60 & 20 & 40 & 60 \\
\hline \multirow{8}{*}{$\begin{array}{l}\text { Delme } \\
\text { kuvveti (N) }\end{array}$} & & Max. & 0.910 & 0.850 & 0.840 & 1.300 & 1.500 & 1.580 \\
\hline & $X^{-}$ & Min. & 0.300 & 0.420 & 0.560 & 1.100 & 1.140 & 1.030 \\
\hline & ekseni & Ort. & 0.554 öd & $0.610^{\circ d}$ & $0.684^{\circ o d}$ & $1.211^{\text {od }}$ & $1.273^{o d d}$ & $1.294^{o d}$ \\
\hline & & SEM & 0.084 & 0.057 & 0.043 & 0.030 & 0.057 & 0.086 \\
\hline & & Max. & 0.460 & 0.450 & 0.450 & 1.890 & 1.400 & 2.050 \\
\hline & Y- & Min. & 0.320 & 0.320 & 0.300 & 1.140 & 1.120 & 1.090 \\
\hline & ekseni & Ort. & 0.359 öd & $0.361 \mathrm{od}$ & $0.386^{\circ \mathrm{od}}$ & $1.463^{\circ 0} d$ & 1.230 od & $1.394 \mathrm{od}$ \\
\hline & & SEM & 0.019 & 0.016 & 0.023 & 0.106 & 0.032 & 0.127 \\
\hline \multirow{8}{*}{$\begin{array}{l}\text { Deformasyon } \\
(\mathrm{mm})\end{array}$} & & Max. & 3.990 & 4.860 & 3.900 & 1.820 & 1.860 & 2.570 \\
\hline & $\mathrm{X}^{-}$ & Min. & 0.620 & 3.130 & 3.000 & 0.890 & 1.140 & 1.240 \\
\hline & ekseni & Ort. & $1.814 b^{* *}$ & $3.982 a$ & $3.360 \mathrm{a}$ & $1.361 b^{* *}$ & $1.451 b$ & $2.060 \mathrm{a}$ \\
\hline & & SEM & 0.429 & 0.198 & 0.109 & 0.128 & 0.097 & 0.172 \\
\hline & & Max. & 1.780 & 4.980 & 5.760 & 1.980 & 1.860 & 2.200 \\
\hline & $\mathrm{Y}^{-}$ & Min. & 0.370 & 3.860 & 3.270 & 1.080 & 1.320 & 1.440 \\
\hline & ekseni & Ort. & $1.227 b^{* *}$ & $4.318 \mathrm{a}$ & $4.324 \mathrm{a}$ & $1.564^{\text {od }}$ & $1.621^{o d}$ & $1.897^{\circ o d}$ \\
\hline & & SEM & 0.193 & 0.146 & 0.292 & 0.130 & 0.090 & 0.097 \\
\hline
\end{tabular}

**: $p<0.01$ öd : önemsiz **: Aynı satırdaki aynı harfler arası fark önemsizdir $(\mathrm{p}<0.01) \quad$ SEM: standart hata

Çizelge 6. Beyaz ve siyah mersin meyvelerinin sıkıştırma testi ve farklı yükleme eksenlerindeki sıkıştırma (compression) kuvveti ile deformasyon değerleri

Table 6. Compression test, compression force and deformation values of white and black myrtle fruits according to the loading axes.

\begin{tabular}{|c|c|c|c|c|c|c|c|c|}
\hline \multirow{3}{*}{$\begin{array}{l}\text { Sikıştırma } \\
\text { testi }\end{array}$} & \multirow{3}{*}{\multicolumn{2}{|c|}{ Yükleme ekseni }} & \multicolumn{3}{|c|}{ Beyaz mersin meyvesi } & \multicolumn{3}{|c|}{ Siyah mersin meyvesi } \\
\hline & & & \multicolumn{3}{|c|}{ Yükleme hızı $\left(\mathrm{mm} \mathrm{min}^{-1}\right)$} & \multicolumn{3}{|c|}{ Yükleme hızı $\left(\mathrm{mm} \mathrm{min}^{-1}\right)$} \\
\hline & & & 20 & 40 & 60 & 20 & 40 & 60 \\
\hline \multirow{7}{*}{$\begin{array}{l}\text { Sikısstırma } \\
\text { kuvveti (N) }\end{array}$} & & Max. & 2.290 & 3.760 & 5.110 & 0.870 & 1.960 & 1.970 \\
\hline & $X^{-}$ & Min. & 0.470 & 1.870 & 0.600 & 0.670 & 0.800 & 1.420 \\
\hline & ekseni & $\begin{array}{l}\text { Ort. } \\
\text { SEM }\end{array}$ & $\begin{array}{l}1.414^{\circ d} \\
0.219\end{array}$ & $\begin{array}{l}2.347^{\text {od }} \\
0.273\end{array}$ & $\begin{array}{l}2.763^{\circ o d} \\
0.575\end{array}$ & $\begin{array}{l}0.804 b^{* *} \\
0.028\end{array}$ & $\begin{array}{c}1.541 a \\
0.170\end{array}$ & $\begin{array}{c}1.746 a \\
0.082\end{array}$ \\
\hline & & Max. & $\frac{0.210}{1.740}$ & 2.800 & 5.930 & 0.910 & 1.970 & 1.990 \\
\hline & $\mathrm{Y}^{-}$ & Min. & 0.800 & 1.190 & 2.300 & 0.660 & 0.780 & 0.730 \\
\hline & ekseni & Ort. & $1.157 c^{* *}$ & $2.131 b$ & $3.406 a$ & $0.766 b^{* *}$ & $1.264 a$ & $1.534 \mathrm{a}$ \\
\hline & & SEM & 0.111 & 0.194 & 0.463 & 0.034 & 0.157 & 0.167 \\
\hline \multirow{8}{*}{$\begin{array}{l}\text { Deformasyon } \\
(\mathrm{mm})\end{array}$} & & Max. & 3.190 & 3.510 & 2.840 & 1.750 & 2.080 & 2.030 \\
\hline & $X^{-}$ & Min. & 1.020 & 1.090 & 1.300 & 0.940 & 0.660 & 1.440 \\
\hline & ekseni & Ort. & $1.616^{o d d}$ & $1.901^{o d}$ & $2.123^{o d} d$ & 1.334 öd & $1.581^{\text {odd }}$ & $1.713^{\text {od }}$ \\
\hline & & SEM & 0.272 & 0.323 & 0.210 & 0.105 & 0.178 & 0.079 \\
\hline & & Max. & 4.800 & 3.550 & 4.300 & 2.280 & 1.930 & 1.740 \\
\hline & $\mathrm{Y}^{-}$ & Min. & 1.530 & 1.400 & 1.840 & 1.240 & 1.200 & 1.600 \\
\hline & ekseni & Ort. & 2.624 od & $2.653^{\circ d}$ & $2.696^{\circ d}$ & $1.588^{\circ o d}$ & $1.656^{\circ d}$ & $1.688^{\circ o d}$ \\
\hline & & $\frac{\text { SEM }}{k \cdot \cdot \cdot 4}$ & 0.399 & 0.289 & 0.328 & 0.129 & 0.100 & 0.021 \\
\hline
\end{tabular}

\footnotetext{
**: $p<0.01$ öd : önemsiz **: Aynı satırdaki aynı harfler arası fark önemsizdir $(\mathrm{p}<0.01) \quad$ SEM: standart hata
}

Çizelge 7. Beyaz ve siyah mersin meyvelerinin kabuk ve meyve etinde belirlenen $L, a, b$, Kroma, Hue açısı ve Kahverengileşme derecesine ait değerler 
Table 7. $L$, $a, b$, Kroma, Hue angle and Browning index degree values of white and black myrtle fruits for skin and flesh.

\begin{tabular}{|c|c|c|c|c|c|}
\hline \multirow{2}{*}{\multicolumn{2}{|c|}{ Renk karakteristikleri }} & \multicolumn{2}{|c|}{ Meyve kabuk renk ölçümleri } & \multicolumn{2}{|c|}{ Meyve eti renk ölçümleri } \\
\hline & & Beyaz & Siyah & Beyaz & Siyah \\
\hline \multirow{4}{*}{$L$} & Max. & 74.87 & 28.69 & 76.25 & 49.39 \\
\hline & Min. & 63.01 & 22.85 & 63.18 & 32.73 \\
\hline & Ort. & 71.14 & 25.36 & 71.19 & 44.16 \\
\hline & SEM $(*)$ & 0.68 & 0.38 & 0.72 & 1.04 \\
\hline \multirow{4}{*}{$a$} & Max. & -0.79 & 1.92 & 2.98 & 7.11 \\
\hline & Min. & -6.80 & 1.32 & -4.05 & 0.40 \\
\hline & Ort. & -4.07 & 1.53 & -0.99 & 3.66 \\
\hline & SEM & 0.44 & 0.04 & 0.36 & 0.40 \\
\hline \multirow{4}{*}{$b$} & Max. & 20.52 & -2.23 & 15.47 & 9.17 \\
\hline & Min. & 16.25 & -4.17 & 8.28 & 1.19 \\
\hline & Ort. & 18.86 & -3.25 & 11.60 & 5.17 \\
\hline & SEM & 0.23 & 0.13 & 0.41 & 0.52 \\
\hline \multirow[t]{4}{*}{ Kroma } & Max. & 21.13 & 4.42 & 15.99 & 9.28 \\
\hline & Min. & 16.33 & 2.67 & 8.39 & 5.31 \\
\hline & Ort. & 19.38 & 3.61 & 11.74 & 6.87 \\
\hline & SEM & 0.28 & 0.12 & 0.42 & 0.26 \\
\hline \multirow[t]{4}{*}{ Hue açısı } & Max. & -70.25 & -55.24 & 87.60 & 87.43 \\
\hline & Min. & -87.52 & -70.92 & -88.50 & 11.67 \\
\hline & Ort. & -78.04 & -64.18 & -50.10 & 52.32 \\
\hline & SEM & 1.23 & 1.16 & 1.12 & 5.20 \\
\hline \multirow{4}{*}{$\begin{array}{l}\text { Kahverengileşme } \\
\text { derecesi }\end{array}$} & Max. & 30.30 & -4.49 & 20.10 & 28.69 \\
\hline & Min. & 22.43 & -10.14 & 12.00 & 12.43 \\
\hline & Ort. & 25.61 & -7.43 & 16.44 & 18.46 \\
\hline & SEM & 0.51 & 0.40 & 0.53 & 0.93 \\
\hline
\end{tabular}

SEM: standart hata

Beyaz mersin meyvesinde meyve kabuk ve meyve eti için a değerlerinin sirasıyla -4.07 ile -0.99 ve siyah mersin meyvesinde ise sirasiyla 1.53 ve 5.17 olduğu görülmüştür. Beyaz mersin meyvelerinin meyve kabuk ve meyve eti için Kroma, Hue açısı ve Kahverengileşme derecesi ortalama değerleri sirasiyla; $19.38,-78.04,25.61$ ve $11.74,-50.10,16.44$ olarak ölçülmüştür. Siyah mersin meyvelerinde ise bu değerler sirasiyla $3.61,-64.18,-7.43$ ve $6.87,52.32$, 18.46 'dır Çalışmada bulunan L aydınlık değerleri açısından, beyaz mersin meyvesi, siyah mersin meyvesine göre daha fazla parlak ve aydınlık değerine sahiptir. Siyah mersin meyvesinin meyve kabuğu ve meyve etinde daha fazla kırmızllık söz konusu iken, beyaz mersin meyvesi daha yeşil renklere sahiptir. Siyah mersin meyvesi kabuğunda daha çok mavilik hakimken, beyaz mersin meyvesinde meyve kabuğunda sarılıkhakimdir. Kroma renk yoğunluğu açısından, beyaz mersin meyvesi siyah mersin meyvesine göre daha yüksek değerde, daha canlı ve açık renk yoğunluğuna sahiptir. Yıldırım ve ark. (2013), Adana ve Tarsus ilçelerinden selekte ettiği 60 mersin genotipine sahip meyvelerin, meyve renk özellikleri içerisinde $L$ değerlerini, 0.93 ile 65.87 aralığında bulurlarken, Kroma renk yoğunluğu değerlerini ise 22.97 ile 78.12 aralığında; Hue açısı (h) değerlerinin, 19.75 ile 50.52 değerleri aralığında değiştiğini açıklamışlardır. Bu çalışmada da, L, Kroma ve Hue açısı değerlerinin sirasiyla beyaz renkli mersin meyvelerinde; 71.14, 19.38 ve -78.04 olduğu; siyah renkli meyvelerde ise $25.36,3.60$ ve -64.18 olduğu belirlenmiştir. Çalışmada elde edilen sonuçlar literatür bilgileriyle uyuşmaktadır. Değerler arasındaki değişimin genetik farklılıklardan kaynaklanabileceği düşünülmektedir.

$\mathrm{Bu}$ çalışmadaki, siyah renkli meyvelerdeki $L$ değerleri, Yıldırım ve ark. (2013)'nin bildirdiği $L$ parlaklık değerleri aralığında, beyaz renkli meyvelerdeki $L$ değerleri ise literatürden daha yüksek bulunmuştur. Ayrıca, çalışmadaki beyaz ve siyah renkli meyvelerdeki Kroma ve Hue açısı değerleri, Yıldırım ve ark. (2013)'nin bildirdiği değerlerden daha düşük değerlerde bulunmuştur.

\section{Kimyasal özellikleri}

Beyaz mersin meyveleri için elde edilen SÇKM ve TEA ortalama değerleri, siyah mersin meyveleri için elde edilen değerlerden daha büyük değerler verirken, $\mathrm{pH}$ değerleri ise, siyah mersin meyvesinde, beyaz renkli meyvelere göre daha yüksek bulunmuştur (Çizelge 8). Yapılan çalışmalarda mersin meyvelerinin kimyasal özellikleri kapsamında, pH değerleri 4.39 ile 6.56; SÇKM değerleri \%11.57-\%29.00 aralığında, TEA değerleri 
ise, 0.17 ile 0.30 aralığında bulunmuştur (Aydın ve Özcan, 2007; Ylldırım ve ark. (2013); Hacıseferoğulları ve ark. (2012). Çalışmada elde edilen sonuçlara göre, beyaz ve siyah mersin meyvelerinin $\mathrm{pH}$ değerlerinin sirasıyla 4.43 ve 5.30 ileliteratür değerleri aralığında, TEA değerlerinin sırasıyla 0.510 ve 0.205 değerleri ileliteratürlere göre daha düşük olduğu, SÇKM değerlerinin ise siyah mersin meyvesinde literatürlere göre daha düşük, beyaz olanlarda ise literatür değerleri aralığında olduğu bulunmuştur. Elde edilen sonuçlar ile literatürler arasındaki farklılıkların, genetik, iklim ve meyvelerin yetiştiği çevre faktörlerinden ve derim zamanından kaynaklanabileceği ifade edilebilir.

Çizelge 8. Beyaz ve siyah mersin meyvelerinin kimyasal özelliklerine ait değerler.

Table 8. Chemical properties of white and black myrtle fruits.

\begin{tabular}{l|llll|llll}
\hline \multirow{2}{*}{ Kimyasal özellikler } & \multicolumn{4}{c|}{ Beyaz mersin meyvesi } & \multicolumn{4}{c}{ Siyah mersin meyvesi } \\
\cline { 2 - 9 } & Max. & Min. & Ort. & SEM & Max. & Min. & Ort. & SEM \\
\hline pH & 4.61 & 4.39 & $\mathbf{4 . 4 8}$ & 0.07 & 5.40 & 5.20 & 5.30 & 0.06 \\
SÇKM (\%) & 13.80 & 13.50 & $\mathbf{1 3 . 6 3}$ & 0.09 & 5.36 & 5.31 & $\mathbf{5 . 3 3}$ & 0.02 \\
TA (\%) & 0539 & 0.492 & $\mathbf{0 . 5 1 0}$ & 0.024 & 0.206 & 0.204 & $\mathbf{0 . 2 0 5}$ & 0.001 \\
\hline
\end{tabular}

SEM: standart hata

\section{SONUÇ ve ÖNERILER}

$\mathrm{Bu}$ çalışmada, siyah ve beyaz mersin meyvelerinin (Myrtus communis L.) fiziksel (geometrik, hacimsel ve renk) özellikleri, mekanik ve kimyasal özelliklerinden elde edilen sonuçlar şöyle özetlenebilir.

-Beyaz renkli mersin meyvelerinin siyah renkli mersin meyvelerine göre daha iri olduğu belirlenmiştir. Geometrik ortalama çap ve yüzey alanı değerleri, beyaz mersin meyvesinde, siyah meyvelerden daha büyük değerdedir.

-Beyaz mersin meyvelerinde, ağırlık ve hacim değerleri daha büyük bulunmuştur.

-Siyah mersin meyveleri meyve eti, meyve kabuk rengine göre $\% 74.13$ oranında daha koyudur.

-Beyaz mersin meyvelerinin sapa tutunma kuvveti, siyah meyvelerden daha yüksektir.

-Siyah mersin meyvelerinin statik sürtünme katsayısı değerleri lastik yüzeyde beyaz olanlara göre daha büyük, galvanizli sac ve PVC sürtünme yüzeylerde ise daha düşüktür.

-Beyaz ve siyah mersin meyvelerinde, yükleme hizlarina göre $X$ - ve $Y$ - eksenleri boyunca delme kuvveti değerleri artarken, $X$ - ekseninde elde edilen değerler, $Y$ - eksenine göre daha yüksek, deformasyon açısından ise $Y$-ekseninde değişimin $X$-eksenine göre daha yüksektir.

-Sıkıştırma kuvveti ve deformasyon değerleri, yükleme hızlarına göre $X^{-}$ve $Y$ - yükleme eksenleri boyunca artış göstermiş ve değişimlerin, $X$ - ekseninde $Y$-eksenine göre daha yüksek belirlenmiştir.

-Beyaz mersin meyvesinin SÇKM ve TEA ortalama değerleri, siyah mersin meyvelerinden daha büyük, pH değeri ise daha düşüktür.

Beyaz ve siyah mersin meyvelerinin biyo-teknik özelliklerinin (fiziksel, mekanik ve kimyasal özellikleri) belirlenmesinin; mersin meyvelerinin özellikle hasat ve hasat sonrası teknolojik işlemlerde, meyvelerin nitelik ve kalitesini korumaya yönelik önlemler alınması için temel mühendislik verilerini elde etmeye yardımcı olacağı düşünülmektedir. Buna ilaveten, hasada ve hasat sonrası meyve işlemeye yönelik olarak mekanik direnç özelliklerinin bilinmesi büyük bir öneme sahiptir. Beyaz mersin meyveleri, daha iri, meyvenin sapa tutunma kuvveti değerleri açısından ticari olarak tüketici istekleri noktasında daha çok kabul görebilir. Buna karşın, siyah mersin meyvesi de mekanik özelliklerden sürtünme katsayısı değerleri açısından lastik yüzey harici galvaniz sac ve PVC yüzeyde daha düşük değerler vermesi, sıkıştırma testi sonucu daha az sıkıştırma kuvvetine göre meydana gelen deformasyon değerleri enerji tüketimi açısından meyvelerin meyve suyuna işlenmesinde istenen bir özellik olarak görülebilir. Genel olarak, her farklı özellik bulunan sonuçların tüketici veya sanayi üretiminde gerekli görülen ihtiyaçlar açısından dikkate alınmasını ortaya koymaktadır. Bu çalışmada, istatistiksel olarak beyaz ve siyah mersin meyveleri karşılaştırılmadığı için şu özellikte, şu renkteki mersin meyvesi daha iyidir demek uygun olmayacaktır. Mersin meyvelerinin biyoteknik özelliklerine ait bulunan sonuçların, genel olarak hasat ve hasat sonrası ürünün işleme, ürünün kalitesi, tüketici istekleri ve ekonomik değer açısından göz önünde bulundurulması önerilmektedir.

\section{Çıkar Çatışması Beyanı}

Makale yazarları aralarında herhangi bir çıkar çatışması olmadığını beyan ederler.

\section{Araştırmacıların Katkı Oranı Beyan Özeti}

Yazarlar makaleye eşit oranda katkı sağlamış olduklarını beyan ederler.

\section{KAYNAKLAR}

Altuntas E, Yildiz M 2007. Effect of moisture content on some physical and mechanical properties of faba bean (Vicia fabaL.) grains. J. Food 
Engineering, 78: 174-183.

Akgül A, Bayrak A 1989. Essential Oil Content and Composition of Myrtle (Myrtus communisL.) Leaves. Doğa, Turk Tarim ve Ormancilik Dergisi., 13: 143-147.

Anonim 2011. Batı Akdeniz Tarımsal Araştırma Enstitüsü Müdürlüğü. http://www.Batem.Gov.Tr/ Mersin_(Myrtus_Communis_L.) Erişim Tarihi: 04.12.2011.

AronneG, Russo D 1997. Carnivorous Mammals As Seed Dispersers of Myrtus Communis in The Mediterranean Shrublands. Plant Biosyst., 131: 189195.

Aydın C, Özcan MM 2007. Determination of Nutritional And Physical Properties Of Myrtle (Myrtus communis L.) Fruits Growing Wild in Turkey. Journal of Food Engineering, 79: 453-458.

Bernalte MJ, Sabio E, Hernandez MT, Gervasini C 2003. Influence of storage delay on quality of "Van" sweet cherry. Postharvest Biology and Technology,28: 303-312.

Boelens MH, Jimenez R 1992. The chemical composition of Spanish myrtle oils. Part II. Journal of Essential Oil Research, 4: 349-353.

Baytop T 1999. Türkiye'de Bitkiler ile Tedavi Geçmişte ve Bugün. Nobel Tip Kitap Evleri, 480 s. İstanbul.

Cemeroglu BS 2013. Gida Analizleri. 480 p. Gida Teknolojisi Press. Ankara.

Diaz AM, Abeger A 1986. Quantative Determination of the Tannin Content of Myrtus Communis L. Seeds, Ann. R. Acad. Farm. 52(1): 117-122.

Doğan A 1978. Mersin Bitkisinin (Myrtus communis L.) Uçucu Yağ Verimi, Yağın Fiziksel, Kimyasal Özellikleri ve Bileşimi Üzerinde Araştırmalar, Ankara, A.Ü. Ziraat Fak. Yay., 678, Ankara.

Erlaçin S, Erciyas E 1978. Myrtus Communis L. (Mersin Bitkisi) Yapraklarının Tanen Yönünden İncelenmesi. Doğa Bilim Dergisi, 2(1): 75-79.

Elfellah MS, Akhter MH, Khan MT 1984. AntiHyperglycaemic Effect of an Extract of Myrtus communis in Streptozotocin-Induced Diabetes in Mice. J. Ethnopharmacol. 11: 275-281.

Ghannadi A, Dezfuly N 2011. Essentialoilanalysis of theleaves of persiantruemyrtle. Int. J. Med. Arom. Plants, 1(2): 48-50.

Hacıseferoğulları H, Özcan MM, Arslan D, Ünver A 2012. Biochemical Compositional And Technological Characterizations of Black And White Myrtle (Myrtus Communis L.) Fruits. Journal of Food Science And Technology, 49: 8288.
İlçim M, Dığrak E 1998. Bazı Bitki Ekstraktlarının Antimikrobiyal Etkilerinin araştırılması. Tubitak, Tr. J. of Biology, 22: 119-125.

İşçi B, Şen F, Güçlü Özdemir A, Kaçar E, Altun A 2014. Effects of Modified Atmosphere Packing (MAP) and Cold Treatment on Organically Grown Table Grape Cultivars. Ege Üniv. Ziraat Fak. Dergisi, 51 (2): 191-199.

Jamoussi B, Romdhane M, Abderraba A, Hassine BB, Gadri AE 2005. Effect of Harvest Time On The Yield and Composition of TunisianMyrtleOils. FlavourAnd Fragrance Journal, 20: 274-277.

McGuire, R.G. 1992. Reporting of objective color measurements. HortScience, 27: 1254-1255.

Mohammadi A, Rafiee S, Emam-Djomeh Z, Keyhanidness A 2008. Kinetic models for colour changes in kiwifruit slices during hot air drying. World Journal of Agricultural Sciences 4 (3): 376383.

Mohsenin N 1980. Physical Properties of Plant and Animal Materials. Gordon and Breach Sciense Publishers, Newyork.

Oğur R 1994. Mersin Bitkisi (MyrtusCommunisL.) Hakkında Bir İnceleme. Çevre Dergisi. 10: 21-25.

Özcan M, Akbulut M 1998. Mersin (Myrtuscommunis L.) meyvesinin bazı fiziksel ve kimyasal özellikleri. Gida, 2: $121-123$.

Özek T, Demirci F, Başer KHC 2000. Chemical Composition of Turkish Myrtle Oil. Journal of Essential Oil Research, 12: 541-544.

Pezhmanmehr M, Dastan D, Ebrahimi SN, Hadian J 2009. Essential oil constituents of leaves and fruits of Myrtus communis L. from Iran Planta Med; 75: PJ164.

Serçe S, Ercişli S, Şengül M, Gündüz K, Orhan E 2010. Antioxidant Activities and Fatty Acid Composition of Wild Grown Myrtle (Myrtus communis L.) Fruits. Pharmacog. Mag. 6: 21, 9-12.

Yıldırım H 2012. Adana ve Mersin Ekolojik Koşullarında Yetişen Mersin Bitkisi (Myrtuscommunis L.'nde Bazı Bitkisel ve Pomolojik Özellikler ile Yaprak Uçucu Yağ Bileşenlerinin Belirlenmesi. Çukurova Üniversitesi, Fen Bilimleri Enstitüsü, Yayınlanmamış Yüksek Lisans Tezi, S. 110. Adana.

Yıldırım H, Paydaş Kargı S, Karabıyık Ş 2013. Adana ve Mersin Ekolojik Koşullarında Doğal Olarak Yetişen Mersin (Myrtus communis L.) Bitkileri Üzerinde Bir Araştırma. Alatarım, 12(1): 1-9. 